Peter S. Ross · Rik L. de Swart · Helen van der Vliet

Linette Willemsen · Arja de Klerk · Geert van Amerongen

Jan Groen · Abraham Brouwer · Ineke Schipholt

Dennis C. Morse $\cdot$ Henk van Loveren

Albert D.M.E. Osterhaus · Joseph G. Vos

\title{
Impaired cellular immune response in rats exposed perinatally to Baltic Sea herring oil or 2,3,7,8-TCDD
}

Received: 7 January 1997 / Accepted: 15 April 1997

\begin{abstract}
While the immunotoxicity of 2,3,7,8-tetrachlorodibenzo-p-dioxin (TCDD) has been well established, the effects of complex environmental mixtures of polyhalogenated aromatic hydrocarbons (PHAHs) are poorly understood. Many PHAHs, including the polychlorinated-biphenyls (PCBs), -dibenzofurans (PCDFs), and dibenzo- $p$-dioxins (PCDDs), possess 'dioxin-like' activities, and accumulate in the aquatic food chain. Organisms occupying high trophic levels may therefore be exposed to concentrations which may present an immunotoxic risk. In this study, pregnant PVG rats were administered a daily oral dose of $1 \mathrm{ml}$ of the following during pregnancy and lactation: (1) oil extracted from herring caught in the relatively uncontaminated Atlantic Ocean; (2) oil extracted from herring caught in the contaminated Baltic Sea; or (3) the Atlantic herring oil extract spiked with 2,3,7,8-TCDD. The daily intakes of aryl hydrocarbon (Ah)-receptor dependent toxic equivalents (TEQ) for mothers were 0.3 in the Atlantic group, 2.1 in the Baltic group, and $134 \mathrm{ng} / \mathrm{kg}$ body wt. in the 2,3,7,8-TCDD positive control group. Immune function and host resistance to rat cytomegalovirus (RCMV) were assessed in offspring aged 11, 25, 46 or 59 days. Rat pups in the positive control TCDD-spiked group
\end{abstract}

Peter S. Ross*·Rik L. de Swart

Seal Rehabilitation and Research Centre,

9968 AG Pieterburen, The Netherlands

Helen van der Vliet · Linette Willemsen · Arja de Klerk Geert van Amerongen · Henk van Loveren · Joseph G. Vos National Institute of Public Health and the Environment, 3720 BA Bilthoven, The Netherlands

Jan Groen · Albert D.M.E. Osterhaus

Erasmus University Rotterdam,

3015 GE Rotterdam, The Netherlands

Abraham Brouwer · Ineke Schipholt · Dennis C. Morse

University of Wageningen,

6703 HE Wageningen, The Netherlands

* Present address ( $\square)$ :

Institute of Ocean Sciences, P.O. Box 6000,

Sidney, BC V8L 4B2, Canada exhibited immunosuppression characterized by reduced thymus weight and cellularity, reduced thymocyte and splenocyte proliferative responses to T-dependent mitogens in vitro, reduced virus-associated natural killer (NK) cell and specific antibody responses. While less pronounced, a similar pattern of effects was observed in the rat pups exposed only to the Baltic Sea herring oil. These immunotoxic effects were transient in both exposure groups, with a time-related recovery in immune function possibly due to the half-life of TCDD in rats and the waning exposure levels in the rapidly growing pups. We previously demonstrated that the same Baltic Sea herring led to impaired natural killer cell and Tlymphocyte function in harbour seals during the course of a long-term captive feeding study. The collective results of these studies in rats and seals indicate the immunotoxic potential of environmental mixtures at current levels in the aquatic environment, and suggest that the developing immune system of young mammals may be at particular risk.

Key words Food chain ' Host resistance Immunotoxicology $\cdot$ Polychlorinated biphenyls (PCBs) 2,3,7,8-tetrachlorodibenzo-p-dioxin (TCDD)

\section{Introduction}

The immunotoxic potential of organochlorine chemicals has been well established in studies on laboratory animals, with polychlorinated biphenyls (PCBs), polychlorinated dibenzo- $p$-dioxins (PCDDs), and polychlorinated dibenzofurans (PCDFs) of particular concern (Vos et al. 1989). However, little is known of the effects of complex environmental mixtures of these polyhalogenated aromatic hydrocarbons (PHAHs) and other compounds. Fish-eating animals occupying high trophic levels in the aquatic food chain often have high burdens of these persistent lipophilic contaminants, and may be at particular risk to their immunotoxic effects. While the mass mortality among harbour (Phoca vitulina) and grey 
(Halichoerus grypus) seals in northern Europe in 1988 was shown to be caused by a newly identified morbillivirus, phocine distemper virus or PDV (Osterhaus and Vedder 1988; Dietz et al. 1989), pollution-induced immunotoxicity could not be ruled out as a contributing factor. We subsequently demonstrated that sub-adult harbour seals fed herring from the contaminated Baltic Sea had impaired natural killer (NK) cell activity (Ross et al. 1996b) and T-lymphocyte responses in vitro (De Swart et al. 1994, 1995) and in vivo (Ross et al. 1995). We then speculated that contaminants played a role in the 1988 mass mortality (De Swart et al. 1996; Ross et al. 1996a).

Following our study using harbour seals, several questions remained unanswered as a result of legal, ethical, and methodological constraints in carrying out immunotoxicological studies in seals. In the first of two parallel studies established to extend our findings in seals, adult PVG rats were fed a mixture of freeze-dried herring prepared from the identical two supplies used in the seal study. Despite similar intakes of contaminants between rats and seals on a body weight basis, there was no evidence of immune alterations in the rats following 4.5 months on the respective diets (Ross et al. 1996c). However, higher virus titres in the salivary glands of rat cytomegalovirus (RCMV)-infected rats fed the Baltic Sea herring suggested a possible immunotoxic effect, which could not be detected using our functional assays. Plasma thyroxine levels were significantly lower in the Baltic group, supporting the idea of a biological effect of PHAH exposure.

The results of several studies indicated the relative insensitivity of the adult rat compared to other species, to the immunotoxic effects of low levels of 2,3,7,8tetrachlorodibenzo- $p$-dioxin (TCDD) and related compounds (Smialowicz et al. 1994). However, the developing immune system of mammals, including that of the rat, has been shown to be particularly sensitive to the immunotoxic action of TCDD (Vos and Moore 1974; Smialowicz et al. 1989; Faith and Moore 1977). Maternal exposure to two doses of $1 \mu \mathrm{g} / \mathrm{kg}$ body wt. of TCDD during gestation and three doses of $1 \mu \mathrm{g} / \mathrm{kg}$ body wt. during lactation resulted in thymus atrophy and reduced phytohaemagglutinin (PHA)-induced spleen cell stimulation in 25-day-old male rat pups (Vos and Moore 1974). In another study, a combined pre- and postnatal exposure to four doses of $5 \mu \mathrm{g} / \mathrm{kg}$ body wt. resulted in more profound and long-lasting effects than those observed in rats exposed only post-natally (Faith and Moore 1977).

Since species of wildlife are not only exposed to lipophilic immunotoxic chemicals during adulthood, but also perinatally, the developing immune system of seals inhabiting contaminated areas may be particularly vulnerable to the effects of environmental contaminants in their diet. The second of our parallel rat studies, presented here, involved a daily exposure of pregnant, and subsequently nursing, female rats to oil extracted from Atlantic and Baltic herring batches used in both of our previous studies. A third group received a mixture of
Atlantic herring oil and 2,3,7,8-TCDD and served as a positive control. All rats received standard rat pellet food in order to limit the variables that could affect immune function to contaminant exposure. We assessed immune function parameters at four time intervals in the offspring of these rats, and evaluated these in the context of host resistance to RCMV infection.

\section{Materials and methods}

\section{Herring oil}

Oil was prepared from North Atlantic herring or Baltic Sea herring by heating in water to $100{ }^{\circ} \mathrm{C}$ (National Institute for Fisheries Research, Ymuiden, The Netherlands). The lipid fraction was mechanically removed, centrifuged once and the supernatant extracted. The resulting oil was mixed with $0.02 \%$ butyl-hydroxytoluene (BHT) as anti-oxidant and aliquoted $(30 \mathrm{ml})$ into $50-\mathrm{ml}$ brown glass bottles. The bottles were then filled with argon gas, sealed and stored at $-20{ }^{\circ} \mathrm{C}$ until use.

\section{Determination of dietary PCB, PCDD and PCDF levels}

Atlantic and Baltic herring oils were analysed for congener-specific planar PCBs (IUPAC numbers 77, 126 and 169) using methods described elsewhere (Van der Velde et al. 1993). Mono-ortho (IUPAC numbers 105, 114, 118, 123, 156, 157, 167 and 189) and diortho (IUPAC numbers 170 and 180) PCB concentrations were determined by multidimensional gas chromatography using methods described by De Boer et al. (1995). Concentrations of all 2,3,7,8 chlorine-substituted PCDD $(n=7)$ and PCDF $(n=10)$ congeners were determined using methods described elsewhere (Liem et al. 1990). Values of TCDD toxic equivalents (TEQ) were then determined for each of these congeners using recently described toxic equivalent factors (TEF) for PCBs (Ahlborg et al. 1994) and PCDDs and PCDFs (Van Zorge et al. 1989).

\section{Study design}

Pregnant rats were divided into three groups and given relatively uncontaminated Atlantic herring oil or Baltic Sea herring oil or Atlantic herring oil containing 2,3,7,8-TCDD. This oil was administered by oral gavage on a daily basis from day 6 of gestation to the weaning of the pups (total of 41 exposure days). Immune function was assessed in four female pups from each nest at different time intervals after birth: pups aged 11, 25, 46 and 59 days ( $n=8$ per group per necropsy). Rat pups of the latter two agegroups were infected with RCMV at 34 days and used in a host resistance study. In addition, one 21-day-old male per nest was used for a study of delayed-type hypersensitivity responses.

\section{Rat study}

Animals were housed and cared for under the supervision of the Animal Ethics Committee of the National Institute of Public Health and the Environment (Bilthoven, The Netherlands), according to the regulations of the European Community Council Directive on the care of laboratory animals (86/609/EEC). Eight-week-old, specific pathogen free (SPF), behaviourally receptive adult female PVG (inbred) rats (PVG/OlaHsd; Harlan-Olac, Zeist, The Netherlands) were bred overnight and subsequently housed separately in sterile filter-top cages. From day 6 of the theoretical pregnancy onwards, all rats $(n=45)$ received by oral gavage $1 \mathrm{ml} /$ day of Atlantic or Baltic herring oil, or a positive control consisting of $27.68 \mathrm{ng} 2,3,7,8$ TCDD (Dow Chemical, Midland, Mich., USA) per ml Atlantic herring oil. Rats received an ad libitum supply of water and 
standard irradiated rat pellet food (no. 1210 SP; Hope Farms, Woerden, The Netherlands) for the duration of the feeding study.

Pregnancy was assessed by weight gain in late gestation, and a minimum of eight successful nests per exposure group were ultimately used in the study. With the exception of the day of, and the day following birth, oil was administered to the mothers on a daily basis until their pups were weaned at 24 days of age. On the day following birth, rat pups were sexed, mean body weights per sex determined, and nests adjusted to four females and three males each. One female pup per nest was later used in each of two necropsies for assessment of immune function and two host resistance studies using RCMV. One male per nest was used to study delayedtype hypersensitivity (DTH) responses to ovalbumin. Other males were used for a separate study.

\section{In vitro tests of immune function}

For the first two immune function necropsies (age of pups 11 and 25 days), one female pup was killed from each of eight nests from each group. Body, thymus, spleen and liver weights were recorded, and the thymus and spleen were placed aseptically in culture medium consisting of RPMI 1640 (Gibco, Grand Island, N.Y., USA), $10 \%$ heat inactivated fetal calf serum (PAA, Linz, Austria), 100 $\mathrm{IU} / \mathrm{ml}$ penicillin, $100 \mu \mathrm{g} / \mathrm{ml}$ streptomycin and $2 \mathrm{mM}$ glutamine. Cell suspensions were prepared as described elsewhere (Ross et al. 1996c), counted by Coulter counter and adjusted to the required concentration.

Cell suspensions of both thymus and spleen were analysed for CD4 and CD8 T-lymphocyte subpopulations by means of surface markers. Using a double-staining method, CD4 cells were labelled using fluorescein isothiocyanate (FITC) labelled ER-2 (Serotec, Oxford, UK) and CD8 cells labelled with biotinylated OX8 (Serotec) monoclonal antibodies as described previously (Ross et al. 1996c). A fluorescence-activated cell scanner (FACS; Becton Dickinson, Rutherford, N.J., USA) was used to measure triplicate samples of 10000 cells. Analysis of mononuclear cell populations was carried out using gates on the basis of forward and side scatter characteristics.

Mitogen-induced lymphocyte stimulations were undertaken using thymus and spleen cell suspensions as described previously (Vos et al. 1984a). Briefly, $2 \times 10^{6}$ thymus cells or $8 \times 10^{5}$ spleen cells were stimulated with the following mitogens: concanavalin A (Con A; final concentration $2 \mu \mathrm{g} / \mathrm{ml}$; Janssen Chimica, Beerse, Belgium), phytohaemagglutinin (PHA; final concentration 1:60; Wellcome Foundation, Darford, UK) or pokeweed mitogen (PWM; final concentration 1:60; Gibco) and placed in 96-well roundbottomed cell culture plates (Greiner, Nürtingen, Germany). Plates were placed in $37{ }^{\circ} \mathrm{C}, 5 \% \mathrm{CO}_{2}$ humidified incubators, and lymphocyte proliferation was assessed by $\left[{ }^{3} \mathrm{H}\right]$ thymidine incorporation after $72 \mathrm{~h}$ of culture.

Natural killer (NK) cell activity in spleen cell preparations was assayed following removal of adherent cells by overnight incubation of the spleen cells at $37{ }^{\circ} \mathrm{C}$ as described elsewhere (De Jong et al. 1980). Natural killer cell activity was measured as the ability of $2 \times 10^{6}$ spleen cells to lyse $1 \times 10^{4}{ }^{51} \mathrm{Cr}$-labelled YAC-1 target cells in a 4-h co-incubation in 96-well cell culture plates. The value was calculated as (radioactivity counts in the supernatant minus spontaneous release by YAC)/(maximal release by YAC cells minus the spontaneous release by YAC cells). Total plasma IgG and IgM levels were determined using enzyme-linked immunosorbent assays (ELISA) as described elsewhere (Vos et al. 1982). Titres were defined as the plasma dilution at which the maximum absorbance signal obtained from pooled plasma samples from the given necropsy day at $450 \mathrm{~nm}$ was reduced by $50 \%$.

\section{Delayed-type hypersensitivity responses}

Eight males aged 21 days from each group were immunized subcutaneously in the neck using a $0.1 \mathrm{ml}$ emulsion of Freund's complete adjuvant (FCA) and $100 \mu \mathrm{g}$ ovalbumin (grade II; Sigma Chemicals, St. Louis, Mo., USA) as described elsewhere (Vos et al. 1984b). These males, plus four non-immunized animals from each group, were tested for DTH reactivity to ovalbumin at age 46 days. For this purpose, rats were anaesthesized and a solution of $10 \mu \mathrm{g}$ ovalbumin in $25 \mu \mathrm{l}$ saline or a control injection of $25 \mu \mathrm{l}$ saline was injected intradermally into each ear. Increase in ear skin thickness was measured at 24 and $48 \mathrm{~h}$ following injection using a digital micrometer (Mitutuyo, Tokyo, Japan). Aspecific swelling induced by ovalbumin in non-immunized rats was subtracted from the mean values obtained in immunized rats.

\section{Host resistance to RCMV}

The two remaining female pups per nest were infected intraperitoneally with $1 \times 10^{5}$ plaque forming units RCMV (obtained from C. Bruggeman, University of Limburg, The Netherlands) in saline at 34 days of age, and necropsies carried out at 46 and 59 days (12 and 25 days respectively following infection). In addition to carrying out the same tests of immune function as described above, the specific spleen cell responses to RCMV in vitro and virus titres in salivary glands were assessed. Spleen cell suspensions were further purified for mononuclear cells with Ficoll (Pharmacia LKB, Uppsala, Sweden) $1.077 \mathrm{~g} / \mathrm{ml}$ density gradient isolation prior to culture and adjusted to $5 \times 10^{6} / \mathrm{ml}$ for both mitogen and RCMV stimulations.

RCMV-specific stimulations consisted of a co-incubation of $3 \times 10^{3}$ para-formaldehyde-fixed RCMV-infected rat embryo cells (REC) and $5 \times 10^{5}$ spleen cells in $150 \mu \mathrm{l} /$ well in 96-well roundbottomed cell culture plates, using methods described previously (Ross et al. 1996c). Plates were incubated at $37{ }^{\circ} \mathrm{C}$ in a $5 \% \mathrm{CO}_{2}$ humidified incubator and $\left[{ }^{3} \mathrm{H}\right]$ thymidine incorporation measured between 72 and $96 \mathrm{~h}$. For the assessment of virus titres, salivary glands during both necropsies were removed aseptically and placed in Eagle basal medium (Gibco) containing 2\% fetal calf serum. A $1: 10(\mathrm{w} / \mathrm{v})$ suspension was frozen at $-86^{\circ} \mathrm{C}$ until the determination of RCMV titres as described elsewhere (Garssen et al. 1995). RCMV-specific total immunoglobulin titres were determined using an indirect ELISA similar to methods described elsewhere (Groen et al. 1989) with slight modifications. Briefly, RCMV cell lysate prepared from rat embryo fibroblasts was coated onto 96-well flatbottomed microtitre plates, and horseradish peroxidase (HRPO)labelled goat anti-rat IgG (Cappel Organon, Turnhout, Belgium) was used as conjugate. Titres were expressed as the plasma dilution giving $50 \%$ reduction of the maximum absorbance signal at $450 \mathrm{~nm}$.

\section{Plasma thyroid hormone measurement}

Total plasma thyroxine (TT4) levels were determined using a chemiluminescence immunoassay (Amersham, Little Chalfont, UK) as previously described (Murk et al. 1994).

\section{Estimation of contaminant intake by pups}

Since nests were standardized to seven pups immediately following birth, the theoretical dosage of TEQs for pups aged 11 and 25 days was calculated on the basis of the cumulative intake of TEQs by the mothers between day 6 of gestation and the two first respective necropsy days. Based on PCB (U- ${ }^{14} \mathrm{C}$-labelled KC-600) dynamics in pregnant and nursing rats (Takagi et al. 1986), a conservative estimate for TEQ dose in our rat pups was calculated using preliminary measurement of a transfer of 3.2 and $4.9 \%$ of the total maternal dose to each rat pup by age 11 and 25 days, respectively, but assuming no loss by mothers via faeces and urine and no metabolic breakdown of contaminants in the pups.

\section{Statistical analysis}

Among-group differences were tested using univariate analysis of variance (ANOVA) for each parameter measured on a given 
Table 1 Breeding study: nest characteristics (mean \pm SEM) 1 day following birth

\begin{tabular}{|c|c|c|c|c|}
\hline & ANOVA & Atlantic & Baltic & TCDD \\
\hline No. successful nests & & $16 / 17$ & $15 / 16$ & $11 / 11$ \\
\hline No. pups per nest & NS & $10.3 \pm 0.47$ & $9.4 \pm 0.66$ & $9.0 \pm 0.65$ \\
\hline No. female pups per nest & NS & $4.67 \pm 0.60$ & $5.00 \pm 0.80$ & $5.38 \pm 0.46$ \\
\hline Weight of female pups (g) & NS & $4.78 \pm 0.09$ & $4.59 \pm 0.22$ & $4.31 \pm 0.11$ \\
\hline Weight of male pups (g) & $* *$ & $5.15 \pm 0.07$ & $5.18 \pm 0.14$ & $4.32 \pm 0.09^{++}$ \\
\hline Weight of mothers $(\mathrm{g})$ & NS & $186 \pm 4.27$ & $192 \pm 2.67$ & $191 \pm 4.63$ \\
\hline
\end{tabular}

ANOVA NS, not significant; $* * P<0.01$

Differences from Atlantic group by $t$-test, ${ }^{++} P<0.01$ necropsy day. If a significant difference was detected, independent $t$-tests were carried out to determine which group was significantly different from the control Atlantic group. For the delayed-type hypersensitivity test, a repeated measures analysis of variance with grouping factors was carried out. Significance levels are indicated by $P$-values of $<0.01$ or $<0.05$ for univariate ANOVA and for independent $t$-tests respectively. Because of the non-normal distribution of virus titres following RCMV infection, a Wilcoxon's signed rank test was used.

\section{Results}

\section{Breeding experiment}

Of the 45 females bred, 44 were pregnant and carried to full term. At 1 day following birth, total pups per nest, female pup numbers and female weights were not significantly different among the three treatment groups of eight nests, although males were significantly smaller in the TCDD group (Table 1). Following the loss of two nests and the standardization of nest size to four female and three male pups, eight randomly selected nests per treatment group were maintained for the duration of the study. Mothers showed no differences in body weights.

\section{Intake of contaminants}

Rat mothers in the Baltic group received 8.5 times higher daily dosage of TEQs than mother rats in the Atlantic group, while those in the TCDD positive control group received a 63 times higher daily dosage than those of the Baltic group (Table 2). Rat pups born to these mothers were exposed via the placenta during pregnancy for 16 days, and via milk until necropsy at 11 days of age or weaning at age 24 days. The intake of aryl hydrocarbon (Ah)-dependent contaminants by rat pups was estimated, with the older pups having a decline in TEQ levels which was associated with increase in body weight (Table 3).

\section{Gross health parameters}

Rat pups born to mothers in the Baltic Sea group exhibited no gross indications of toxicity, with organ weights being similar to those of the Atlantic group (Table 4). On the other hand, rat pups born to mothers
Table 2 Estimated intake of TCDD toxic equivalents (TEQs) per rat mother expressed as ng TEQ/kg body weight unless otherwise indicated (TCDD 2,3,7,8-tetrachlorodibenzo-p-dioxin)

\begin{tabular}{lccc}
\hline & Atlantic & Baltic & TCDD \\
\hline Daily dose (ng TEQ) & 0.05 & 0.44 & 27.7 \\
Daily intake & 0.25 & 2.12 & 134 \\
Cumulative intake at birth & 3.92 & 33.9 & 2143 \\
Cumulative intake at pup & 6.62 & 57.2 & 3616 \\
$\quad$ age 11 days & 10.1 & 86.9 & 5490 \\
\hline
\end{tabular}

Table 3 Estimated cumulative intake of 2,3,7,8-TCDD TEQs for each rat pup using PCB transfer data of Takagi et al. (1996) expressed as absolute daily dose (ng) or on a body weight basis in ng TEQ/kg body weight ( $P C B$ Polychlorinated biphenyl)

\begin{tabular}{llcc}
\hline & Atlantic & Baltic & TCDD \\
\hline $\begin{array}{l}\text { Cumulative dose at age } \\
\quad 11 \text { days }(\mathrm{ng})\end{array}$ & 0.04 & 0.35 & 22.2 \\
$\begin{array}{l}\text { Cumulative intake at age } \\
\quad 11 \text { days }(\mathrm{ng} / \mathrm{kg})\end{array}$ & 2.03 & 19.9 & 1440 \\
$\begin{array}{l}\text { Cumulative dose at age } \\
\quad 25 \text { days (ng) }\end{array}$ & 0.09 & 0.83 & 52.1 \\
$\begin{array}{l}\text { Cumulative intake at age } \\
25 \text { days }(\mathrm{ng} / \mathrm{kg})\end{array}$ & 1.83 & 17.3 & 1363 \\
\hline
\end{tabular}

in the TCDD positive control group had a number of significant effects, including reduced body weights at the time of all necropsies, reduced liver weights at the time of the second and last necropsies, and reduced thymus weights at the time of the first three immune function necropsies. However, there was no significant effect of TCDD on the growth rates of these pups, indicating the existence of normal growth patterns following birth.

Of the gross immunological parameters, thymocyte numbers (Table 5) and thymus subpopulations (Table 6) were most affected by contaminants, while spleen cell subpopulations showed more resiliency. Of particular note was a pattern of reduced $\mathrm{CD} 4+/ \mathrm{CD} 8+$ ratios in the thymus, particularly in the TCDD group, until the fourth necropsy. This was not the case in the spleen, where no alterations in $\mathrm{CD} 4+/ \mathrm{CD} 8+$ ratios were detected (Fig. 1). There were no significant differences in total $\operatorname{IgM}$ and $\operatorname{IgG}$ titres among the three groups during the course of the experiment (Table 7). However, total IgM titres had a significantly greater increase immediately following RCMV infection as indicated by the 
Table 4 Gross health parameters. Data are of mean \pm SEM, (RCMV Rat cytomegalovirus)

\begin{tabular}{|c|c|c|c|c|}
\hline Parameter/age of pup & ANOVA & Atlantic & Baltic & TCDD \\
\hline \multicolumn{5}{|l|}{ Body weight (g): } \\
\hline 11 days & ** & $19.8 \pm 0.54$ & $18.2 \pm 1.16$ & $15.4 \pm 0.59^{++}$ \\
\hline 25 days & ** & $48.7 \pm 1.24$ & $48.0 \pm 1.36$ & $38.2 \pm 1.23^{++}$ \\
\hline 46 days (+RCMV) & $* *$ & $112.5 \pm 2.16$ & $109.6 \pm 2.88$ & $97.1 \pm 3.66^{++}$ \\
\hline 59 days (+RCMV) & $* *$ & $140.1 \pm 1.61$ & $137.8 \pm 2.7$ & $118.6 \pm 2.6^{++}$ \\
\hline \multicolumn{5}{|c|}{ Growth (ratio from birth): } \\
\hline 11 days & NS & $4.2 \pm 0.18$ & $4.3 \pm 0.41$ & $3.6 \pm 0.20$ \\
\hline 25 days & NS & $10.4 \pm 0.45$ & $10.8 \pm 0.83$ & $8.9 \pm 0.35$ \\
\hline 46 days (+RCMV) & NS & $23.4 \pm 0.8$ & $24.3 \pm 1.4$ & $22.7 \pm 1.0$ \\
\hline 59 days (+RCMV) & NS & $29.4 \pm 0.74$ & $30.7 \pm 2.0$ & $27.7 \pm 1.0$ \\
\hline \multicolumn{5}{|l|}{ Thymus weight (mg): } \\
\hline 11 days & $* *$ & $56.9 \pm 3.52$ & $47.6 \pm 4.31$ & $34.5 \pm 2.00^{++}$ \\
\hline 25 days & ** & $147 \pm 5.40$ & $140 \pm 5.38$ & $87.7 \pm 10.4^{++}$ \\
\hline 46 days (+RCMV) & ** & $276 \pm 12.1$ & $289 \pm 10.7$ & $241 \pm 4.86^{+}$ \\
\hline 59 days $(+\mathrm{RCMV})$ & NS & $248 \pm 9.3$ & $250 \pm 5.77$ & $233 \pm 7.20$ \\
\hline \multicolumn{5}{|l|}{$\begin{array}{l}\text { Thymus/body weight } \\
\text { ratio }(\times 1000) \text { : }\end{array}$} \\
\hline 11 days & ** & $2.86 \pm 0.13$ & $2.70 \pm 0.09$ & $2.23 \pm 0.08^{++}$ \\
\hline 25 days & $* *$ & $2.82 \pm 0.14$ & $2.92 \pm 0.08$ & $2.29 \pm 0.27^{+}$ \\
\hline 46 days $(+\mathrm{RCMV})$ & NS & $2.45 \pm 0.06$ & $2.63 \pm 0.06$ & $2.50 \pm 0.08$ \\
\hline 59 days (+RCMV) & NS & $1.77 \pm 0.06$ & $1.81 \pm 0.03$ & $1.98 \pm 0.08$ \\
\hline \multicolumn{5}{|l|}{ Spleen weight (mg): } \\
\hline 11 days & NS & $101 \pm 6.38$ & $94.7 \pm 9.21$ & $89.9 \pm 4.75$ \\
\hline 25 days & * & $232 \pm 9.30$ & $225 \pm 7.38$ & $190 \pm 22.2^{++}$ \\
\hline 46 days $(+\mathrm{RCMV})$ & NS & $363 \pm 11.02$ & $363 \pm 8.10$ & $353 \pm 12.4$ \\
\hline 59 days $(+\mathrm{RCMV})$ & NS & $359 \pm 5.87$ & $344 \pm 7.78$ & $325 \pm 14.1$ \\
\hline \multicolumn{5}{|l|}{ Liver weight (mg): } \\
\hline 11 days & NS & $585 \pm 18.4$ & $547 \pm 34.8$ & $535 \pm 17.0$ \\
\hline 25 days & $*$ & $2252 \pm 74.6$ & $2277 \pm 53.3$ & $2000 \pm 223^{++}$ \\
\hline 46 days $(+\mathrm{RCMV})$ & NS & $5360 \pm 99.9$ & $5370 \pm 200$ & $5092 \pm 196$ \\
\hline 59 days $(+\mathrm{RCMV})$ & $* *$ & $6552 \pm 179$ & $6570 \pm 265$ & $5640 \pm 82.6^{++}$ \\
\hline
\end{tabular}

ANOVA NS, not significant; $* P<0.05 ; * * P<0.01$

$t$-test ${ }^{+} P<0.05 ;{ }^{++} P<0.01$ difference between titre on day 46 compared to day 25 $(P<0.05$; results not shown $)$ in the TCDD group of rats.

\section{Mitogen-induced thymus and spleen cell proliferation}

While there were no notable differences in gross health or immune parameters between rat pups of the groups treated with Atlantic and Baltic herring oil, there were indications of cellular immunosuppression in the Baltic group as exemplified by functional tests. The young rat pups of the TCDD group had lower Con A, PHA and PWM-induced thymus cell proliferative responses, and lower Con A- and PWM-induced spleen lymphocyte responses (Figs. 2 and 3). Effects were most notable in 11-day-old rat pups of both Baltic and TCDD groups, when Con A-induced spleen lymphocyte stimulation was significantly lower (Fig. 3). While the effects on the Baltic group of rats were not always significant, there appeared to be a gradient of Atlantic > Baltic > TCDD for mitogen-induced stimulations of both thymus and
Table 5 Thymus and spleen cellularity (mean \pm SEM)

\begin{tabular}{|c|c|c|c|c|}
\hline & ANOVA & Atlantic & Baltic & TCDD \\
\hline \multicolumn{5}{|c|}{ No. thymus cells $\left(\times 10^{6}\right)$} \\
\hline 11 days & ** & $121 \pm 15.8$ & $87.4 \pm 7.2$ & $57.0 \pm 4.2^{++}$ \\
\hline 25 days & $* *$ & $226 \pm 14.2$ & $272 \pm 23.2$ & $130 \pm 14.6^{++}$ \\
\hline 46 days $(+\mathrm{RCMV})$ & NS & $403 \pm 24.3$ & $416 \pm 25.4$ & $372 \pm 22.0$ \\
\hline 59 days (+RCMV) & $*$ & $508 \pm 23.4$ & $418 \pm 17.0^{++}$ & $393 \pm 33.8^{++}$ \\
\hline \multicolumn{5}{|l|}{ No. spleen cells $\left(\times 10^{6}\right)$} \\
\hline 11 days & NS & $46.4 \pm 2.62$ & $47.2 \pm 5.02$ & $45.5 \pm 4.02$ \\
\hline 25 days & NS & $145 \pm 10.5$ & $147.4 \pm 11.1$ & $120.1 \pm 15.0$ \\
\hline 46 days $(+\mathrm{RCMV})$ & NS & $280 \pm 16.7$ & $279 \pm 22.7$ & $277 \pm 19.9$ \\
\hline 59 days ( $+\mathrm{RCMV})$ & NS & $248 \pm 10.2$ & $231 \pm 8.57$ & $231 \pm 10.9$ \\
\hline
\end{tabular}

ANOVA NS, not significant; $* P<0.05$; $* * P<0.01$

$t$-test ${ }^{++} P<0.01$ 
Table 6 Flow cytometry analyses of thymus and spleen cell subpopulations (mean \pm SEM)

\begin{tabular}{|c|c|c|c|c|}
\hline & ANOVA & Atlantic & Baltic & TCDD \\
\hline \multicolumn{5}{|c|}{ No. CD4 in thymus $\left(\times 10^{6}\right)$ : } \\
\hline 11 days & $*$ & $7.54 \pm 1.14$ & $5.88 \pm 0.52$ & $2.88 \pm 0.28^{+}$ \\
\hline 25 days & $* *$ & $19.7 \pm 1.44$ & $23.0 \pm 1.92$ & $10.6 \pm 1.06^{++}$ \\
\hline 46 days $(+\mathrm{RCMV})$ & $*$ & $41.7 \pm 2.68$ & $41.5 \pm 2.94$ & $32.2 \pm 2.44^{+}$ \\
\hline 59 days (+RCMV) & * & $54.9 \pm 2.47$ & $48.2 \pm 2.73$ & $40.4 \pm 4.04^{++}$ \\
\hline \multicolumn{5}{|c|}{ No. CD8 in thymus $\left(\times 10^{6}\right)$ : } \\
\hline 11 days & $* *$ & $8.90 \pm 0.90$ & $8.82 \pm 0.86$ & $5.04 \pm 0.30^{+}$ \\
\hline 25 days & $* *$ & $10.8 \pm 0.98$ & $13.1 \pm 1.16$ & $7.08 \pm 0.60^{+}$ \\
\hline 46 days (+RCMV) & NS & $16.5 \pm 1.60$ & $18.5 \pm 1.45$ & $18.6 \pm 1.42$ \\
\hline 59 days $(+\mathrm{RCMV})$ & * & $29.1 \pm 1.44$ & $24.3 \pm 1.82$ & $21.9 \pm 2.32^{+}$ \\
\hline \multicolumn{5}{|l|}{$\begin{array}{l}\text { No. } \text { CD } 4+/ \text { CD } 8+ \\
\text { in thymus }\left(\times 10^{6}\right) \text { : }\end{array}$} \\
\hline 11 days & $* *$ & $99.6 \pm 13.4$ & $67.2 \pm 7.44^{+}$ & $47.0 \pm 3.84^{++}$ \\
\hline 25 days & NS & $187 \pm 11.9$ & $226 \pm 19.4$ & $106 \pm 8.22^{++}$ \\
\hline 46 days (+RCMV) & NS & $333 \pm 19.6$ & $344 \pm 21.1$ & $309 \pm 18.9$ \\
\hline 59 days (+RCMV) & * & $409 \pm 20.5$ & $333 \pm 13.3^{++}$ & $320 \pm 27.5^{+}$ \\
\hline \multicolumn{5}{|c|}{ No. CD4 in spleen $\left(\times 10^{6}\right)$ : } \\
\hline 11days & NS & $2.10 \pm 0.24$ & $2.08 \pm 0.28$ & $1.44 \pm 0.20$ \\
\hline 25 days & $* *$ & $16.1 \pm 1.10$ & $16.2 \pm 0.52$ & $11.72 \pm 0.96^{++}$ \\
\hline 46 days $(+\mathrm{RCMV})$ & ND & ND & $\mathrm{ND}$ & ND \\
\hline 59 days (+RCMV) & NS & $82.4 \pm 3.32$ & $78.6 \pm 3.18$ & $77.2 \pm 5.13$ \\
\hline \multicolumn{5}{|c|}{ No. CD8 in spleen $\left(\times 10^{6}\right)$ : } \\
\hline 11 days & NS & $1.32 \pm 0.10$ & $1.28 \pm 0.18$ & $0.94 \pm 0.08$ \\
\hline 25 days & $* *$ & $6.06 \pm 0.36$ & $5.70 \pm 0.24$ & $4.54 \pm 0.32^{++}$ \\
\hline 46 days $(+\mathrm{RCMV})$ & ND & ND & ND & ND \\
\hline 59 days (+RCMV) & NS & $37.0 \pm 1.14$ & $36.5 \pm 1.49$ & $33.9 \pm 1.17$ \\
\hline
\end{tabular}

ANOVA NS, not significant; ND, not determined; $* P<0.05 ; * * P<0.01$ $t$-test ${ }^{+} P<0.05 ;{ }^{++} P<0.01$
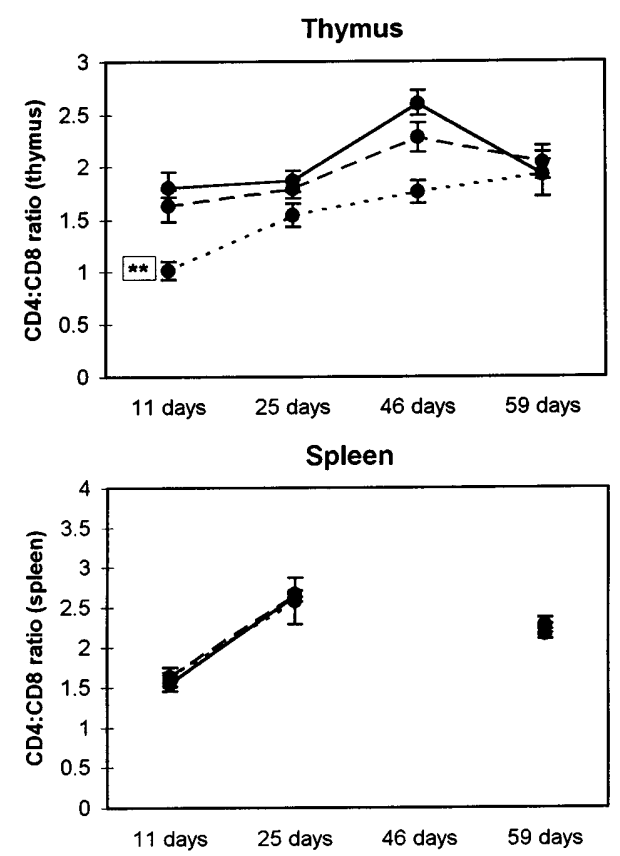

Fig. $1 \mathrm{CD} 4 / \mathrm{CD} 8$ ratios in thymus (above) and spleen (below) mononuclear cells before and after rat cytomegalovirus (RCMV) infection in rat pups of the Atlantic (solid line), Baltic (long dash), and TCDD (short dash) groups. Data represent mean \pm SEM of eight pups. CD4 and CD8 analyses were not determined for spleen cell suspensions in pups aged 46 days spleen cells in the first two immune function necropsies. Following RCMV infection in the older rat pups, proliferation to mitogens by thymus cells appeared to have recovered, while responses of spleen lymphocytes to PHA were lower in the TCDD group.

\section{Delayed-type hypersensitivity responses}

Ovalbumin-specific DTH responses were observed, with immunized rats having greater swellings than non-immunized rats $24 \mathrm{~h}$ after intradermal injection. A gradient of Atlantic $>$ Baltic $>$ TCDD was observed at the peak swelling time of $24 \mathrm{~h}$, though there were no significant differences (Fig. 4). Specific IgG responses to ovalbumin revealed an inverse pattern to that observed for many of the other immune function parameters (TCDD $>$ Baltic $>$ Atlantic) and to that observed for IgM, although the differences were not significant (Table 7).

\section{Natural killer cell activity}

Basal NK cell activity was virtually undetectable in the youngest rats, and was higher in the TCDD pups at age 25 days than the other two groups of rats (Fig. 5). 
Table 7 Immunoglobulin titres and specific antibody responses. Data are of mean \pm SEM $(p . i$. Post infection $D T H$ delayedtype hypersensitivity)

\begin{tabular}{|c|c|c|c|c|}
\hline & ANOVA & Atlantic & Baltic & TCDD \\
\hline \multicolumn{5}{|l|}{ Total IgM titre $\left(\times 10^{3}\right)$ : } \\
\hline 11 days & NS & $2.2 \pm 0.3$ & $1.8 \pm 0.2$ & $1.5 \pm 0.2$ \\
\hline 25 days & NS & $10.1 \pm 1.1$ & $9.8 \pm 1.0$ & $8.7 \pm 0.9$ \\
\hline 46 days (+RCMV) & NS & $27.8 \pm 3.6$ & $30.2 \pm 5.1$ & $35.7 \pm 3.4$ \\
\hline 59 days (+RCMV) & NS & $26.5 \pm 2.3$ & $25.1 \pm 2.4$ & $21.7 \pm 2.2$ \\
\hline \multicolumn{5}{|l|}{ Total IgG titre $\left(\times 10^{3}\right)$ : } \\
\hline 11 days & NS & $518 \pm 79$ & $452 \pm 54$ & $357 \pm 50$ \\
\hline 25 days & NS & $492 \pm 102$ & $632 \pm 137$ & $633 \pm 75$ \\
\hline 46 days (+RCMV) & NS & $399 \pm 64$ & $300 \pm 57$ & $369 \pm 71$ \\
\hline 59 days $(+\mathrm{RCMV})$ & NS & $329 \pm 61$ & $289 \pm 47$ & $399 \pm 72$ \\
\hline \multicolumn{5}{|c|}{$\begin{array}{l}\text { Ovalbumin-specific antibody } \\
\text { titre in DTH males: }\end{array}$} \\
\hline IgM & NS & $57 \pm 19$ & $44 \pm 13$ & $45 \pm 13$ \\
\hline $\operatorname{IgG}\left(\times 10^{3}\right)$ & NS & $19.6 \pm 7.9$ & $23.5 \pm 2.6$ & $31.7 \pm 7.8$ \\
\hline \multicolumn{5}{|l|}{ RCMV-specific IgG titre: } \\
\hline 46 days (12 days p.i.) & NS & $184 \pm 13$ & $230 \pm 31$ & $203 \pm 18$ \\
\hline 59 days (25 days p.i.) & $* *$ & $529 \pm 88$ & $241 \pm 25^{++}$ & $324 \pm 54^{+}$ \\
\hline
\end{tabular}

ANOVA NS, not significant; $* * P<0.01$

$t$-test ${ }^{+} P<0.05 ;{ }^{++} P<0.01$
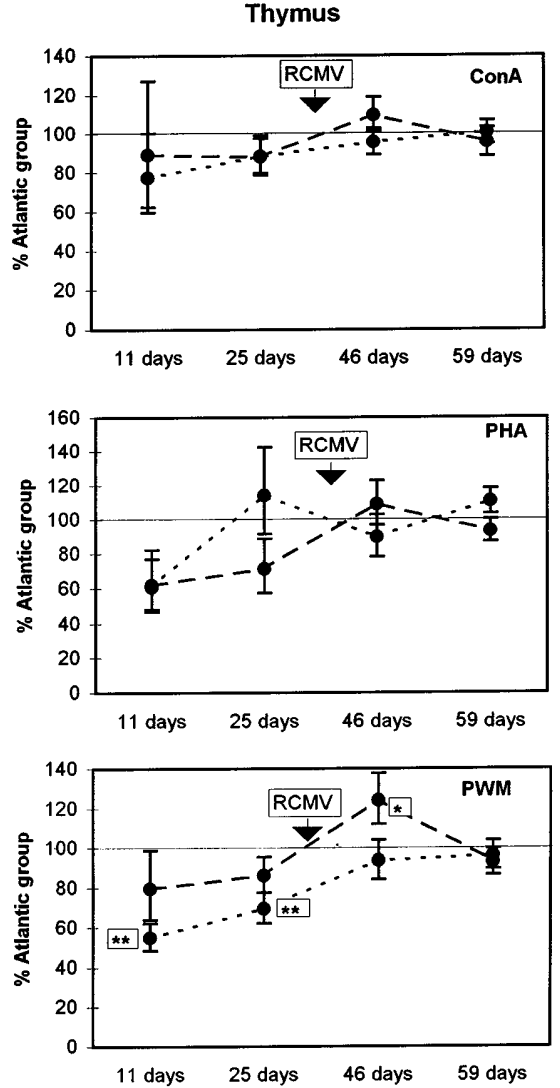

Fig. 2 Mitogen-induced proliferative responses of thymus cells expressed as a percentage of the Atlantic group in Baltic (long dash) and TCDD (short dash) groups $(n=8)$ before and after RCMV infection. Data were natural log-transformed and means expressed as a percentage of the Atlantic group in order to correct for age-related differences. Error bars representing $66 \%$ confidence interval of this ratio were calculated as the anti-log transformation of the differences between the groups on the log scale \pm SEM of these differences. (ConA concanavalin A, $P H A$ phytohaemagglutinin, $P W M$ pokeweed mitogen)
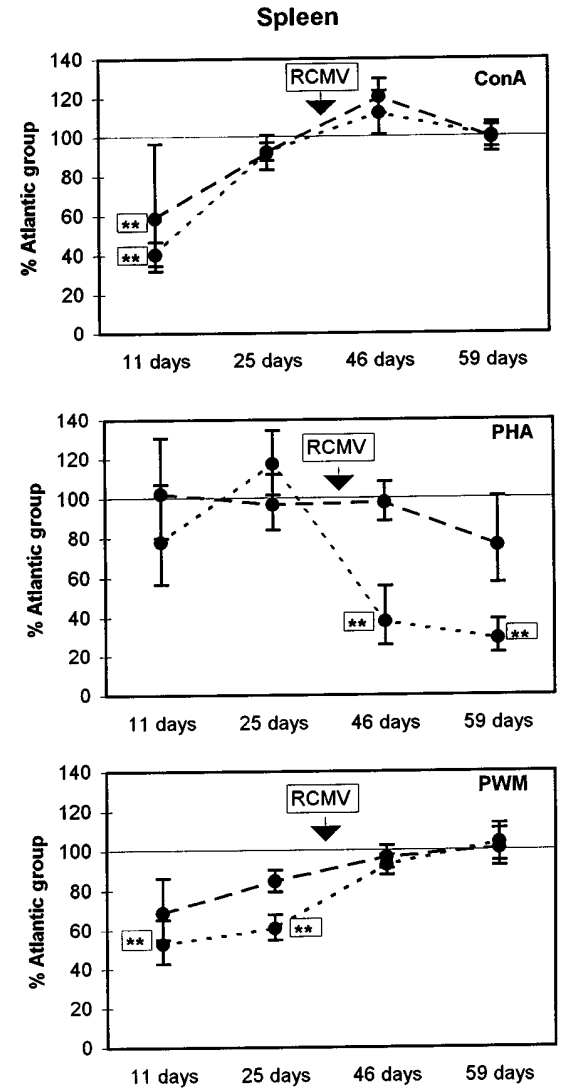

Fig. 3 Mitogen-induced proliferative responses of spleen cells expressed as a percentage of the Atlantic group in Baltic (long dash) and TCDD (short dash) groups before and after RCMV infection. Data were corrected for numbers of cells per organ, natural log-transformed and means expressed as a percentage of the Atlantic group in order to correct for age-related differences. Further details are as given in the legend to Fig. 2 


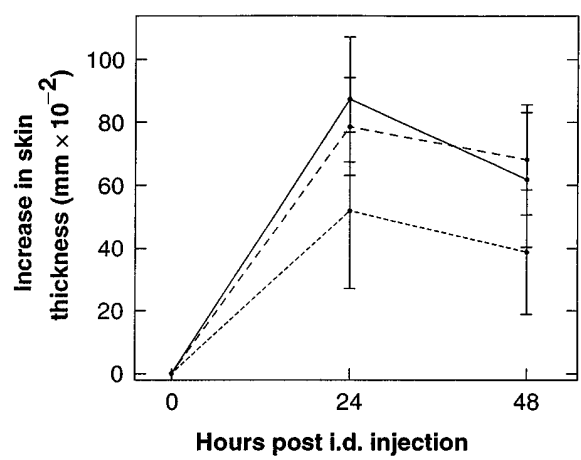

Fig. 4 Delayed-type hypersensitivity responses to ovalbumin in male pups of the Atlantic (solid line), Baltic (long dash) and TCDD (short dash) groups. Data represent the mean absolute increase \pm SEM of $n=8$ pups following subtraction of the mean responses of nonimmunized animals to antigen (i.d. intradermal)

However, when corrected to incorporate virus infection, the RCMV-associated increase in NK cell activity was significantly lower in both Baltic and TCDD rat pups than in the Atlantic group (ratio of NK cell activity in 46-day-old/25 day-old pups).

\section{Host resistance to RCMV}

Proliferative responses of spleen lymphocytes to RCMV-infected stimulator cells were significantly lower in the TCDD group than the Atlantic group in pups at age 46 days, but there was no significant effect in the Baltic group (Fig. 6). Total RCMV-specific immunoglobulin titres did not differ among groups at 12 days following infection, but were significantly lower in both the Baltic and TCDD groups at 25 days post-infection (Table 7). Virus titres were not significantly different among groups on both necropsy days after either 12 or 25 days of infection (Table 8).

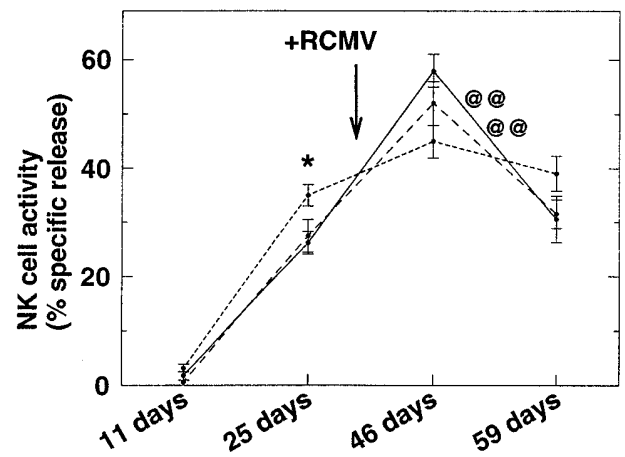

Fig. 5 Natural killer (NK) cell activity in Atlantic (solid line), Baltic (long dash) and TCDD (short dash) groups, expressed as natural cytotoxic activity of spleen cells using ${ }^{51} \mathrm{Cr}$-labelled YAC-1 tumour cells as targets. Data represent mean \pm SEM of $n=8$ pups. Differences are indicated as: (i) for basal or spontaneous activity $\left({ }^{*} P<0.05\right)$; and (ii) for virus-associated increase following RCMV infection at 37 days (calculated as specific release at 46 days/specific release at 25 days; @@P $<0.01$ )

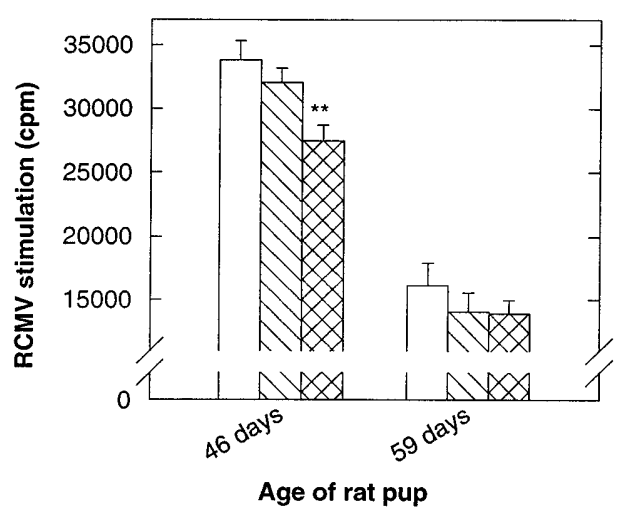

Fig. 6 RCMV-induced stimulation in vitro of spleen cells isolated from rats infected for 12 days (46-day-old rats) or 25 days (59-day-old rats), in Atlantic (open column), Baltic (single hatched column), or TCDD (double hatched column) groups. Bars represent mean gross counts per minute for $n=8$ rats \pm SEM of wells co-incubated with RCMV-infected rat embryo cells following 4 days of incubation

\section{Plasma thyroid hormone}

Total thyroxine levels in plasma did not differ between Atlantic and Baltic groups at any age, but were significantly lower in the 11- and 25-day-old TCDD group (Table 9).

\section{Discussion}

The immune systems of the rats in our study were clearly in a developmental phase, evidenced by the increasing numbers of thymus and spleen cell subpopulations, increasing NK cell activity and mitogen-induced lymphocyte proliferation with age. The plasma $\operatorname{IgM}$ and $\operatorname{IgG}$ levels in rat pups with time reflected the patterns of maternal transfer via milk (IgG) consistent with the endothelio-chorial placentation of rats and endogenous production by the pups (IgM and $\operatorname{IgG})$. Because of the age-related immunological changes, the evaluation of an effect of contaminants was restricted to a comparison among the treatment groups of a given age. Exposure to the contaminants did not lead to any effects on maternal body weight, number of successful nests, or number of pups per nest in any of the treatment groups.

Rat pups of the positive control 2,3,7,8-TCDD group had an estimated cumulative intake of $1.4 \mu \mathrm{g} / \mathrm{kg}$ body weight by 25 days of age, a dose which led to significant immunotoxic effects. While this exposure level did result in some gross pathological effects (reflected by body, spleen and liver weights) at certain points during the study, growth was not affected, suggesting that the animals developed normally following birth. The thymus proved to be most notably affected, with reduced weight (absolute and body weight adjusted) in the younger animals, and reductions of thymocyte numbers and function at various points. In addition, the proliferative responses of splenocytes were reduced at various time points. The TCDD-related suppression of the immune 
Table 8 RCMV titres in the salivary glands of rat pups. Data are of mean \pm SEM

\begin{tabular}{lllll}
\hline & ANOVA & Atlantic & Baltic & TCDD \\
\hline 46-day-old pups (12 days RCMV) & NS & $5.51 \pm 0.30$ & $5.69 \pm 0.33$ & $5.03 \pm 0.36$ \\
59-day-old pups (25 days RCMV) & NS & $5.84 \pm 0.28$ & $6.23 \pm 0.14$ & $5.42 \pm 0.24$ \\
\hline
\end{tabular}

ANOVA NS, Not significant

\begin{tabular}{lllll}
\hline & ANOVA & Atlantic & Baltic & TCDD \\
\hline 11-day-old pups & $*$ & $47.7 \pm 2.0$ & $45.3 \pm 2.5$ & $38.4 \pm 2.8^{+}$ \\
25-day-old pups & $* *$ & $29.0 \pm 1.0$ & $28.5 \pm 1.1$ & $15.7 \pm 1.2^{++}$ \\
46-day-old pups & NS & $33.9 \pm 2.9$ & $28.7 \pm 2.5$ & $32.3 \pm 3.0$ \\
59-day-old pups & NS & $32.6 \pm 2.9$ & $35.0 \pm 1.5$ & $39.0 \pm 2.7$ \\
\hline
\end{tabular}

ANOVA NS, Not significant; $* P<0.05$; $* * P<0.01$

$t$-test ${ }^{+} P<0.05 ;^{++} P<0.01$
Table 9 Plasma thyroxine levels $(\mathrm{nmol} / \mathrm{l})$. Data are of mean \pm SEM function parameters led to a diminished capacity of the rats to mount specific cellular and antibody responses following RCMV infection. The lack of effect on RCMV titres in the TCDD group of rats may have reflected the transient nature of the immunosuppression, with an immunological recovery overcoming any effects on virus titres. Alternatively, host resistance to this virus may involve other features of the immune system which were not measured.

Rat pups exposed to the Baltic Sea herring contaminants had an estimated cumulative intake of only $17 \mathrm{ng} /$ $\mathrm{kg}$ body weight at age 25 days. While no gross pathological effects were observed in this group, there were significant effects on immune function. Though less pronounced than in the TCDD group, the Baltic rats showed transient reductions in thymus cellularity and splenocyte functionality. Virus-associated effects were also observed, with RCMV-associated increase in NK cell activity and $\operatorname{IgG}$ titres being significantly lower than in the Atlantic group.

The immunological effects of contaminants in both the TCDD and Baltic groups indicate an effect at the level of the thymus or thymocyte precursors. The thymus is a sensitive target for 2,3,7,8-TCDD in rats (De Heer et al. 1994) and other laboratory animals, with thymus atrophy being attributed to reduced maturation of the thymocytes (Blaylock et al. 1992; Greenlee et al. 1985) and reduced seeding of the thymus by bone marrow progenitors (Fine et al. 1990). In addition to noticeable effects on the actual thymus, populations of mature circulating T-lymphocytes were also impaired.

The impaired virus-associated increase in NK cell activity following RCMV infection in the two exposure groups was consistent with observations of other studies (Selgrade et al. 1992; Yang et al. 1994). In the first of these studies, the authors concluded that virus-associated increases in NK cell activity correlated better with mortality following virus infection than basal, or spontaneous, NK activity in exposed animals. The lower RCMV-specific antibody titres observed at 25 days postinfection in the two exposure groups suggest an effect of contaminants on the humoral response, possibly re- flecting an effect on B-cells, T-helper cells, or their precursors. In addition, the impaired RCMV-specific T-cell responses may indicate that activity of cytotoxic Tlymphocytes was affected in TCDD-exposed rats (Ross et al. 1996c).

Suppression of spontaneous NK cell activity, T-cell function in vitro, antibody responses to ovalbumin, and delayed type hypersensitivity responses in vivo were previously demonstrated to occur during a long-term captive feeding study of harbour seals fed the same Atlantic and Baltic herring used in this study (for reviews see De Swart et al. 1996; Ross et al. 1996a). The concordance of immune effects between the perinatally exposed rat pups in this study and juvenile seals exposed to the Baltic Sea herring contaminants provides the basis for a comparison of the two species. While there were inevitable differences in the study designs and the observed effects, both rats and harbour seals had impaired T-cell and NK cell responses following dietary exposure to contaminants in the Baltic herring. Since the application of certain invasive techniques or a host resistance model would not have been appropriate in the seal study, additional information has been generated in this parallel rat model. The impaired T-cell immunity in the harbour seals fed Baltic Sea herring is speculated possibly to have reflected toxicity at the level of the thymus, and the seals may have also had diminished specific immune responses following virus infection.

The estimated dose of TEQs to which the pregnant rats and their pups were exposed in the current work was relatively low. The 11-day-old rat pups of the group exposed to Baltic herring oil exhibited immunological alterations when their mothers had received a daily dose of only $2 \mathrm{ng} / \mathrm{kg}$ and a total cumulative TEQ dose of 57 $\mathrm{ng} / \mathrm{kg}$ body wt., at which point we estimated the cumulative pup exposure to be $20 \mathrm{ng} / \mathrm{kg}$ body wt. While the effects on the thymus and on cellular immunity are consistent with the known effects of 2,3,7,8-TCDD (Vos and Luster 1989), most studies have utilized dosages far exceeding those used here, and relied primarily upon acute exposures administered on a once only or limited basis. Earlier studies demonstrating the developing im- 
mune system of rats to be relatively sensitive to the immunotoxic effects of 2,3,7,8-TCDD used multiple maternal doses of 1 or $5 \mu \mathrm{g} / \mathrm{kg}$ body wt. (Vos and Moore 1974; Faith and Moore 1977). Pre- and postnatal exposure was shown to result in more profound effects than postnatal exposure alone (Faith and Moore 1977), while the long-lasting effects may have reflected the high initial dosage and resulting maintenance of immunotoxic levels of TCDD in rat pups of those studies. We exposed the TCDD group of female rats in this study to a daily dosage (28 ng per rat; $134 \mathrm{ng} / \mathrm{kg}$ body wt.), which would lead to a cumulative exposure of approx. $5 \mu \mathrm{g} / \mathrm{kg}$ body wt. at weaning, a dosage which has been demonstrated to be immunotoxic in laboratory rats (De Heer et al. 1994; Ross et al. 1996c). Therefore this group served as a positive control in the study. The partial recovery observed in our rat pups is likely to have reflected the removal of the contaminant source (milk) at weaning, the metabolic loss of 2,3,7,8-TCDD in the rat pups, and the rapid growth of pups during this period. The estimated 24-day half-life of 2,3,7,8-TCDD in rats (Rose et al. 1976) implies that the rapidly growing pups in our study would have diminishing body burdens during nursing and after weaning.

In another feeding study, a reduction in $\operatorname{IgM}, \operatorname{IgG}$ and $\operatorname{IgA}$ plaque-forming responses to sheep red blood cells was observed in Ah-responsive $\mathrm{C} 57 \mathrm{Bl} / 6$ adult mice fed salmon from the relatively contaminated Lake Ontario for 4 months (Cleland et al. 1989). Owing to relative sensitivity of mice to the immunotoxic actions of TCDD (Smialowicz et al. 1994), the different contaminant characteristics in the diets and the choice of immune function tests used, a comparison is difficult of these results to those obtained in our studies. However, this study also supports the idea that anthropogenic contaminants in the aquatic food chain are immunotoxic to mammals.

A possible synergistic or antagonistic effect of different PHAH congeners cannot be ruled out to explain the observed immunotoxicity in the Baltic group, nor can a contribution of non-Ah receptor contaminants. More detailed analyses of contaminant residues in the herring are presented elsewhere (Ross et al. 1996c). However, what appears to be a dose-related pattern of immunotoxic effects among the three groups (Atlantic $<$ Baltic $<$ TCDD) may suggest a similar mechanism of immunotoxic action in the Baltic and TCDD groups. Immunotoxicity by organochlorines has been shown to be largely mediated by the Ah receptor (Safe 1990; Nagarkatti et al. 1984). The TCDD group of rat pups was exposed to the Ah-prototype immunotoxicant, 2,3,7,8-TCDD (a very small amount of other organochlorines were present in the relatively uncontaminated Atlantic herring oil), while the Baltic group was exposed to a complex mixture of lipophilic PHAH compounds. Since PCBs comprised the majority of total TEQ in the Baltic Sea herring lipid (Ross et al. 1996a,c), PCBs would have been largely responsible for an Ah-dependent immunotoxicity in rat pups of the Baltic group (the total contribution of all PCDDs to the TEQ in Baltic herring was $<10 \%$, whereas PCBs contributed nearly $60 \%$ ).

We did not detect any changes in plasma thyroxine levels in the Baltic group of rats, even though prenatally exposed rats have been shown to be sensitive to the effects of PCBs (Morse et al. 1993). While an earlier effect may conceivably have disappeared by the time of first necropsy at 11 days, our results also suggest that immunotoxicity may occur irrespective of thyroid alterations in animals exposed perinatally to a complex mixture of contaminants. Thyroid hormone levels are considered a reliable indicator of exposure to certain PHAH compounds and some of their metabolites (Brouwer et al. 1986; Brouwer and Van den Berg 1983); the lower thyroxine levels in the TCDD group at the time of the first two necropsies support this suggestion. In our previous study of adult rats, a reduction in plasma thyroid hormone levels was observed while, other than differences in RCMV loads in the salivary glands, immune alterations were undetectable (Ross et al. 1996c).

The immunological alterations observed in the Baltic rat pups were largely transient and were less pronounced than in the TCDD group. However, even subtle alterations in immune status can affect host resistance, leading to increased susceptibility to infection (Luster et al. 1993). The fact that a lipid extract of herring caught from the Baltic Sea could lead to immunological alterations, however small, should be of concern, particularly in a species which has been shown to be relatively insensitive to the effects of TCDD.

The concordance in immune effects between perinatally exposed rats in this study and juvenile seals (De Swart et al. 1996; Ross et al. 1996a) provides a basis for comparison of the two species. Extrapolation of our observations of an effect on both non-antigen- and RCMV-directed immune responses in rat pups suggests that seals exposed perinatally may be more sensitive to the effects of immunotoxic environmental contaminants than was indicated by our previous studies of juvenile seals. Whereas the exposure to immunotoxic contaminants in the rat pups ceased at weaning, predators at the top of the food chain would be exposed to an ongoing source of TCDD-like contaminants in their diets. Thus seals inhabiting contaminated environments would be exposed perinatally and subsequently via their diet, and may therefore be expected to suffer from prolonged, if not permanent, immunotoxicity. The described results suggest chronic exposure to low levels of environmental contaminants presents a risk to the developing immune system. Since both the Atlantic and Baltic herring used in this study were destined for human consumption, such results are not only relevant to seals and other aquatic wildlife, but also to human health concerns.

Acknowledgements The authors gratefully acknowledge the contributions of the following people to these studies: Jan Assink, Sjors Groenemeyer, Ben van Middelaar, Djien Liem, Marcel Menkhorst, Coen Moolenbeek, Nico Schmidt, Herman Naring, Aldert Piersma and Elze de Ruiter. 


\section{References}

Ahlborg UG, Becking GC, Birnbaum LS, Brouwer A, Derks HJGM, Feeley M, Golor G, Hanberg A, Larsen JC, Liem AKD, Safe SH, Schlatter C, Waern F, Younes M, Yrjanheikki E (1994) Toxic equivalency factors for dioxin-like PCBs. Chemosphere 28: 1049-1067

Blaylock BL, Holladay SD, Comment CE, Heindel JJ, Luster MI (1992) Exposure to tetrachlorodibenzo- $p$-dioxin (TCDD) alters fetal thymocyte maturation. Toxicol Appl Pharmacol 112: 207213

Brouwer A, Van den Berg KJ (1983) Early decrease in retinoid levels in mice after exposure to low doses of polychlorinated biphenyls. Chemosphere 12: 555-557

Brouwer A, Van den Berg KJ, Blaner WS, Goodman DS (1986) Transthyretin (prealbumin) binding of PCBs, a model for the mechanism of interference with vitamin A and thyroid hormone metabolism. Chlor Dioxins Relat Comp 15: 1699-1706

Cleland GB, McElroy PJ, Sonstegard RA (1989) Immunomodulation in $\mathrm{C} 57 \mathrm{Bl} / 6$ mice following consumption of halogenated aromatic hydrocarbon-contaminated Coho salmon (Oncorhyncus kisutch) from Lake Ontario. J Toxicol Environ Health 27: 477-486

De Boer J, Dao QT, Wester PG, Bowadt S, Brinkman UAT (1995) Determination of mono-ortho substituted chlorobiphenyls by multidimensional gas chromatography and their contribution to TCDD equivalents. Anal Chim Acta 300: 155-165

De Heer C, Verlaan APJ, Penninks AH, Vos JG, Schuurman H-J, Van Loveren H (1994) Time course of 2,3,7,8-tetrachlorodibenzo- $p$-dioxin (TCDD)-induced thymic atrophy in the Wistar rat. Toxicol Appl Pharmacol 128: 97-104

De Jong WH, Steerenberg PA, Ursem PS, Osterhaus ADME, Vos JG, Ruitenberg EJ (1980) The athymic nude rat: III. Natural cell-mediated cytotoxicity. Clin Immunol Immunopathol 17: 163-172

De Swart RL, Ross PS, Vedder LJ, Timmerman HH, Heisterkamp SH, Van Loveren H, Vos JG, Reijnders PJH, Osterhaus ADME (1994) Impairment of immune function in harbor seals (Phoca vitulina) feeding on fish from polluted waters. Ambio 23: 155159

De Swart RL, Ross PS, Timmerman HH, Vos HW, Reijnders PJH, Vos JG, Osterhaus ADME (1995) Impaired cellular immune response in harbour seals (Phoca vitulina) feeding on environmentally contaminated herring. Clin Exp Immunol 101: 480486

De Swart RL, Ross PS, Vos JG, Osterhaus ADME (1996) Impaired immunity in harbour seals (Phoca vitulina) exposed to bioaccumulated environmental contaminants: review of a longterm study. Environ Health Perspect 104 (Suppl 4): 823-828

Dietz R, Heide-Jörgensen M-P, Härkönen T (1989) Mass deaths of harbor seals (Phoca vitulina) in Europe. Ambio 18: 258-264

Faith RE, Moore JA (1977) Impairment of thymus-dependent immune functions by exposure of the developing immune system to 2,3,7,8-tetrachlorodibenzo- $p$-dioxin (TCDD). J Toxicol Environ Health 3: 451-464

Fine JS, Silverstone AE, Gasiewicz TA (1990) Impairment of prothymocyte activity by 2,3,7,8-tetrachlorodibenzo- $p$-dioxin. J Immunol 144: 1169-1176

Garssen J, Van der Vliet H, De Klerk A, Goettsch W, Dormans J, Bruggeman CA, Osterhaus ADME, Van Loveren H (1995) A rat cytomegalovirus infection model as a tool for immunotoxicity testing. Eur J Pharmacol-Environ Toxicol 292: 223-231

Greenlee WF, Dold KM, Irons RD, Osborne R (1985) Evidence for direct action of 2,3,7,8-tetrachlorodibenzo- $p$-dioxin (TCDD) on thymic epithelium. Toxicol Appl Pharmacol 79: 112-120

Groen J, Broeders H, Spijkers I, Osterhaus ADME (1989) Comparison of an enzyme-linked immunosorbent assay, an immunofluorescence assay and a hemagglutination inhibition assay for detection of antibodies to K-papovavirus in mice. Lab Anim Sci 39: 21-23
Liem AKD, De Jong APJM, Marsman JA, Den Boer AC Groenemijer GS, Den Hartog RS, De Korte GAL, Hoogerbrugge R, Kootstra PR, Van't Klooster, HA (1990) A rapid clean-up procedure for the analysis of polychlorinated dibenzo-p-dioxins and dibenzofurans in milk samples. Chemosphere 20: 843-850

Luster MI, Portier C, Pait DG, Rosenthal GJ, Germolec DR, Corsini E, Blaylock BL, Pollock P, Kouchi Y, Craig W, White KL, Munson AE, Comment CE (1993) Risk assessment in immunotoxicology 2. Relationships between immune and host resistance tests. Fundam Appl Toxicol 21: 71-82

Morse DC, Groen D, Veerman M, Van Amerongen CJ, Koëter HBWM, Smits Van Prooije AE, Visser TJ, Koeman JH, Brouwer A (1993) Interference of polychlorinated biphenyls in hepatic and brain thyroid hormone metabolism in fetal and neonatal rats. Toxicol Appl Pharmacol 122: 27-33

Murk AJ, Bosveld ATC, van den Berg M, Brouwer A (1994) Effects of polyhalogenated hydrocarbons (PHAHs) on biochemical parameters in chicks of the common tern (Sterna hirundo). Aquat Toxicol 30: 91-115

Nagarkatti PS, Sweeney GD, Gauldie J, Clark DA (1984) Sensitivity to suppression of cytotoxic $\mathrm{T}$ cell generation by $2,3,7,8$ tetrachlorodibenzo- $p$-dioxin (TCDD) is dependent on the Ah genotype of the murine host. Toxicol Appl Pharmacol 72: 169176

Osterhaus ADME, Vedder EJ (1988) Identification of virus causing recent seal deaths. Nature 335: 20

Rose JQ, Ramsey JC, Wentzler TH, Hummel RA, Gehring PJ (1976) The fate of 2,3,7,8-tetrachlorodibenzo- $p$-dioxin following single and repeated oral doses to the rat. Toxicol Appl Pharmacol 36: 209-226

Ross PS, De Swart RL, Reijnders PJH, Van Loveren H, Vos JG, Osterhaus ADME (1995) Contaminant-related suppression of delayed-type hypersensitivity and antibody responses in harbor seals fed herring from the Baltic Sea. Environ Health Perspect 103: $162-167$

Ross PS, De Swart RL, Addison RF, Van Loveren H, Vos JG, Osterhaus ADME (1996a) Contaminant-induced immunotoxicity in harbour seals: wildlife at risk? Toxicology 112: 157-169

Ross PS, De Swart RL, Timmerman HH, Reijnders PJH, Vos JG, Van Loveren H, Osterhaus ADME (1996b) Suppression of natural killer cell activity in harbour seals (Phoca vitulina) fed Baltic Sea herring. Aquat Toxicol 34: 71-84

Ross PS, Van Loveren H, De Swart RL, Van der Vliet H, De Klerk A, Timmerman HH, Van Binnendijk RS, Brouwer A, Vos JG, Osterhaus ADME (1996c) Host resistance to rat cytomegalovirus (RCMV) and immune function in adult PVG rats fed herring from the contaminated Baltic Sea. Arch Toxicol 70: $661-671$

Safe S (1990) Polychlorinated biphenyls (PCBs), dibenzo-p-dioxins (PCDDs), dibenzofurans (PCDFs), and related compounds: environmental and mechanistic considerations which support the development of toxic equivalency factors (TEFs). CRC Crit Rev Toxicol 21: 51-88

Selgrade MJK, Daniels MJ, Dean JH (1992) Correlation between chemical suppression of natural killer cell activity in mice and susceptibility to cytomegalovirus: rationale for applying murine cytomegalovirus as a host resistance model and for interpreting immunotoxicity testing in terms of disease. J Toxicol Environ Health 37: 123-137

Smialowicz RJ, Riddle MM, Rogers RR, Luebke RW, Copeland CB (1989) Immunotoxicity of tributyltin oxide in rats exposed as adults or pre-weanlings. Toxicology 57: 97-111

Smialowicz RJ, Riddle MM, Williams WC, Diliberto JJ (1994) Effects of 2,3,7,8-tetrachlorodibenzo- $p$-dioxin (TCDD) on humoral immunity and lymphocyte subpopulations - differences between mice and rats. Toxicol Appl Pharmacol 124: 248-256

Takagi Y, Aburada S, Hashimoto K, Kitaura T (1986) Transfer and distribution of accumulated (14-C) polychlorinated biphenyls from maternal to fetal and suckling rats. Arch Environ Contam Toxicol 15: 709-715 
Van der Velde EG, Marsman JA, De Jong APJM, Hoogerbrugge R, Liem AKD (1993) Analysis and occurrence of toxic planar PCBs, PCDDs and PCDFs in milk by use of carbosphere activated carbon. Chemosphere 28: 693-702

Van Zorge JA, Van Wijnen JH, Theelen RMC, Olie K, Van den Berg M (1989) Assessment of the toxicity of mixtures of halogenated dibenzo- $p$-dioxins and dibenzofurans by use of toxicity equivalency factors (TEF). Chemosphere 19: 1881-1895

Vos JG, Moore JA (1974) Suppression of cellular immunity in rats and mice by maternal treatment with 2,3,7,8-tetrachlorodibenzo-p-dioxin. Int Arch Allergy 47: 777-794

Vos JG, Krajnc EI, Beekhof P (1982) Use of the enzyme-linked immunosorbent assay (ELISA) in immunotoxicity testing. Environ Health Perspect 43: 115-121

Vos JG, De Klerk A, Krajnc EI, Kruizinga W, Van Ommen B, Rozing J (1984a) Toxicity of bis(tri- $n$-butyltin)oxide in the rat.
II. Suppression of thymus-dependent immune responses and of parameters of nonspecific resistance after short-term exposure. Toxicol Appl Pharmacol 75: 387-408

Vos JG, van Logten MJ, Kreeftenberg JG, Kruizinga W (1984b) Effect of triphenyltin hydroxide on the immune system of the rat. Toxicology 29: 325-336

Vos JG, Luster MI (1989) Immune alterations. In: Kimbrough $\mathrm{RD}$, Jensen $\mathrm{S}$ (eds) Halogenated biphenyls, terphenyls, naphthalenes, dibenzodioxins and related products. Elsevier, Amsterdam, pp 295-322

Yang YG, Lebrec H, Burleson GR (1994) Effect of 2,3,7,8 tetrachlorodibenzo- $p$-dioxin (TCDD) on pulmonary influenza virus titer and natural killer (NK) activity in rats. Fundam Appl Toxicol 23: 125-131 